\title{
African-American Youth and Exposure to Community Violence: Supporting Change from the Inside
}

\author{
Anita Jones Thomas, Devin Carey, Kia-Rai Prewitt, Edna Romero, \\ Maryse Richards, and Barbara Velsor-Friedrich
}

Loyola University Chicago

\begin{abstract}
Children's exposure to community violence and its effects on child health outcomes have become a major public health concern in this country, and African-American youth are at greatest risk. Participatory action research, as a vehicle for promoting social justice, is one tool that can be used to address community violence. This article describes the use of focus groups as a way to give African-American youth a voice in providing solutions to violence exposure through the revision of curricula (coping skills and civic engagement). Participants reported a variety of stressors, including exposure to violence, and a lack of coping strategies and adult support for processing violence. Suggestions for curriculum revisions are included. The process of conducting groups, lessons learned from the process, and implications for researchers interested in promoting social justice are discussed.
\end{abstract}

Keywords. African-American youth, violence prevention, focus groups

Since the early 1990 's, children's exposure to community violence, whether as a victim, an offender, or a witness to violence, and its effects on child health outcomes have become a major public health concern (CDC, 2010; Glodich, 1998). Exposure to violence in low-income urban children and adolescents has been linked to symptoms of depression and anxiety (Cooley-Quille, Boyd, Frantz, \& Walsh, 2001; GormanSmith \& Tolan, 1998; Mazza \& Reynolds, 1999; Schwab-Stone et al., 1995), PTSD (Berton \& Stab, 1996; Fitzpatrick \& Boldizar, 1993; Overstreet \& Braun, 2000) and poorer academic functioning (Schwartz \& Gorman, 2003). Finally, exposure to community violence is strongly associated with problem behaviors such as delinquency and perpetrating aggression and violence (Fowler, Tompsett, Braciszewski, JacquesTiura, \& Baltes 2009). Counseling psychologists, as well as social service and healthcare professionals, have an obligation to advance social justice, particularly in the area of exposure to violence that seems to disproportionately affect African American youth. 


\section{Overview of Community Violence and Interventions}

\section{Definition and Causes}

There is a lack of consensus on the definition of community violence. The National Center for Children Exposed to Violence (2010) defines community violence as "the exposure to acts of interpersonal violence committed by individuals who are not intimately related to the victim" (para. 1). These acts can include sexual assault, burglary, use of weapons, muggings, the sounds of bullet shots, as well as the presence of teen gangs, drugs, and racial divisions (National Center for Children Exposed to Violence, 2010). Kliewer and Sullivan (2008) define community violence as experiencing, seeing, or hearing about violence in one's home, school, or neighborhood which can lead to adjustment difficulties in youth. In a review of 23 empirical studies, the definition of community violence focused on the child or parent experiencing, witnessing and/or hearing about instances of violence. However, the review concluded that the lack of a clear definition as well as the use of many different instruments to measure the concept has led to difficulty in comparing findings and integrating them into the current body of knowledge regarding community violence (Trickett, Duran \& Horn, 2003).

The systemic causes of community violence are complex and multi-leveled. Co-occurring factors operate at multiple levels and include neighborhood contexts such as the prevalence of gangs and drugs, access to weapons, and the damaging effects of pervasive, chronic poverty (Sampson, Raudenbush, \& Earls, 1997); family factors such as parenting practices and supports (Hammack, Richards, Luo, Edlynn, \& Roy, 2004); and individual factors, including lack of academic achievement, emotion dysregulation, aggression, and cognitive distortions (e.g., Johnson, 2006; Lambert, et al, 2011; Robinson, et al, 2011; Sweeney, Goldner, \& Richards, 2011). The causes of community violence differ by subgroups (e.g., gender, ethnicity, urban/rural, developmental age) and by complex interactions among the factors (Boyce, Robinson, \& Richards, 2011; Hammond \& Arias, 2011).

In 2000, homicide was the second leading cause of death for persons 15-24 years and the fourth leading cause of death in persons 1-14 years (Tuma, Loeber, \& Lochman, 2006). A recent nationwide survey of high school students reveals that about $6 \%$ reported not going to school on one or more days in the 30 days preceding the survey because they felt unsafe at school or on their way to and from school (CDC, 2010). About 32\% of high school students reported being in a physical fight in the 12 months before the survey and $20 \%$ of students reported being bullied on school property. Approximately, 700,000 youth between the ages of 10 to 14 are treated in emergency departments each year for injuries sustained due to violence-related assaults (CDC 2009). In addition, 16 persons between the ages of 10-24 are murdered each day (CDC, 2009). Recent research has identified demographic groups most at risk for exposure to community violence and established a multitude of harmful consequences of this exposure. The demographic predictors of exposure to community violence indicate that African- Americans (Fowler, et al, 2009), males (Ceballo, Dahl, Aretakis, \& Ramirez, 2001; Weist, Acosta, \& Youngstrom, 2001) and older youth (Klaus \& Rennison, 2002) are more often exposed to violence. African-American youth living in urban, low-income communities have been shown to be more at risk for being exposed to community violence than any other population in the United States (Aisenberg \& Herrenkohl, 2008; Garbarino, Hammond, Mercy \&Yung, 2004; Stein et al., 2003).

\section{Programs to Resolve Community Violence}

With the goal of eliminating systemic causes of violence, churches, community and civic organizations, governmental agencies, and school systems have responded in a variety of ways (Hammond \& Arias, 2011); gun buy-back programs aim to eliminate guns on the streets and anti-bullying programs at schools hope to foster a climate of safety. Schools and communities have also established escort services for children in dangerous neighborhoods, and offer after school programs as an alternative to gang involvement and to create safe zones (Sanderson \& Richards, 2010). Although many violence prevention 
programs have been implemented, the problem is not abating as seen in statistics on youth and community violence (CDC, 2009). Many programs are designed to prevent violence from occurring by promoting anger management and emotion regulation. However, these programs may have limited success in reducing the systemic or contextual causes of violence in urban areas, and they do not address the internal experiences or psychological reactions of children and youth who are often most vulnerable to negative outcomes from constant exposure to violence. Finally, they ignore the positive contributions and resilience of youth.

\section{Community-Based Participatory Action Research}

African American children and youth are often not allowed to give voice to their concern in the designing of interventions aimed at reducing the effect of exposure to violence and community stressors. Parham and McDavis (1987) discuss the importance of including individuals in efforts to create change as inclusion recognizes the individual's sense of agency in promoting change. One benefit of communitybased participatory action research (CBPAR) is that it often brings solutions to problems from within, an important component of social justice work. Interventionists who come from outside of the target communities often have conflicting value systems which may compromise service delivery (Reese \& Vera, 2007). Engaging in CBPAR gives voice to the target population, often serving as a way to promote social justice (Costa, Herbert, \& Macaulay, 2004) and to promote culturally sensitive service delivery.

Community-based participatory action research with African-American school-age children and youth remains scarce. The few studies that have employed CBPAR with African-American youth largely focused on establishing new life skills to prevent behaviors such as violence, school performance, drug use, and early sexual behavior (Bryant, 2000; Caldwell, Rafferty, Reischl, Loney, \& Brooks, 2010; Marcus et al., 2004; Ozer et al, 2008). Researchers argue that preventing these behaviors will enhance the group's critical consciousness, and thus, provide the catalyst for social change. For example, a community-based participatory action study by Marcus and colleagues (2004) found that African-American adolescents who participated in a faith-based program called Project BRIDGE reported significantly less marijuana and other drug use and an increased fear of contracting HIV/AIDS than their control counterparts. Caldwell and colleagues (2010) found that interventions aimed at deterring risky behaviors in African-American pre-adolescent males are strengthened when fathers are included in the program. In addition to changing or preventing behaviors, CBPAR interventions can also create a sense of empowerment in AfricanAmerican youth, which in turn bolsters their confidence and their critical consciousness (Bryant, 2000).

The primary goal for this project was to engage in community participatory research with AfricanAmerican adolescents in a high risk urban community so that curricula could be revised and implemented for use in reducing negative effects from exposure to violence. This was to be accomplished through enhancing resilience and/or enhancing civic engagement. Revision was needed to make the curricula developmentally appropriate, focused on stress in general and violence exposure in particular, and appropriate to the low income neighborhoods in which the youth lived. The first curriculum, Coping Skills (CST) is a cognitive-behavioral strategy with the goal of teaching adolescents personal and social coping skills to assist them in dealing with potential stressors and stress reactions encountered in their daily lives (Forman, 1993). CST has been successfully used by researchers in the management of teens with diabetes and asthma. (Ambrosino, Fennie, Whittemore, Jaser, \& Grey, 2008; Grey, Boland, Davidson, Li, \& Tamborlane, 2000; Grey, Boland, Davidson, Yu, \& Tamborlane, 1999; It has also been used specifically with African-American populations dealing with asthma (Velsor-Friedrich, Pigott, \& Srof, 2005). CST focuses on the following skills: 1) social problem-solving; 2) effective communication; 3) cognitive behavior modification; 4) conflict resolution; and 5) stress reduction.

The second curriculum, Civic Engagement Curriculum (CEC) was developed to enhance the capacity of youth to take better control of themselves through understanding and action, to develop leadership skills and bring about positive change in their environments (Richards, Sanderson, \& Celio, 2011), and was developed for urban and ethnic minority youth in particular. Based in theories of resilience and positive 
psychology (Larson, 2000; The Search Institute, 2006), this approach builds capacity and enhances the potential of youth to engage in constructive community change. The CEC was designed to enhance capacity to work with others, resolve conflicts more effectively, develop initiative, and become more empowered to bring about constructive change in the community.

This paper will provide a summary of lessons learned from working with this population from the first component of the project which was to revise the CST and CEC curricula through focus groups with African American youth. We hope to provide suggestions for researchers and practitioners interested in reducing risks related to exposure to violence for African American youth, particularly those interested in violence as a social justice concern.

\section{Project Overview}

Engaging in dialogue with at-risk groups often empowers them to create effective solutions for addressing concerns. Due to the connection between exposure to violence and psychological distress, academic performance, and physical health, it is imperative to empower African American children and youth to more effectively cope with violence exposure. While the elimination of stress and community violence may not be achievable, the development of protective coping factors that foster resilience in these youth can promote positive youth outcomes (Edlynn, Gaylord-Harden, Richards, \& Miller 2008; Hammack, Richards, Luo, Edlynn, \& Roy, 2004). This leads not only to positive effects in individuals, but can also result in quality improvements in youth health outcomes. As researchers and mental health professionals, we desired to revise and adapt the CST and CEC to improve coping with exposure to violence in African American middle school age youth.

\section{Method: Summary of Focus Group Process}

\section{Researchers}

The interdisciplinary research team was comprised of three faculty, one white woman in nursing, one white woman in clinical psychology, and one African American woman in counseling psychology, along with five graduate students two White women and one White man in clinical psychology, and two AfricanAmerican women in counseling psychology. The two white faculty had been involved with research in using the CST with African American students with asthma, and one had been instrumental in developing the CEC. The African- American faculty had been involved in consultation with community-based prevention programs for African-American youth, and had qualitative research experience. She was instrumental in connecting to sites to recruit students for this study. All three faculty are invested in community-based research and intervention services designed to improve the lives of urban youth. The five graduate students have been trained in multicultural psychology and social justice.

\section{Participants}

The research team conducted a series of focus groups at schools in high-risk neighborhoods in a large urban community. One investigator had a long-term relationship as a consultant and clinician with an after-school community program designed to enhance educational achievement for both children and families. The team met with the director of the center to discuss the research programs and the feasibility of recruiting the program participants for the project. After receiving buy-in from the director, two of the investigators met with program coordinators and staff at the community-based agency to discuss the implementation of the project. Similar to the director, the program coordinators and staff were very enthusiastic about the programs, but they directly expressed concerns about the principals of their schools and their response to the program. Schools were selected for the curricula revision and implementation being mindful of the administration of each potential school. 
Two schools were selected to participate and one series of focus groups was held in each school. Both schools are located in one of two communities with the highest levels of violent crime in the city (Eno \& Shaker, 2008). The street crime included frequent gang wars, shootings, and sexual assaults in the southern area of a large urban Midwestern city. Both schools were predominantly African American $(99 \%)$, low-income $(98 \%)$, and had very high percentages of students performing below state standards in reading and math. Based on approval conditions of the cooperating schools, it was determined that using after-school time was preferable to time taken away from the daily class schedule. Researchers asked the after-school staff to identify ten children who had experienced a number of daily hassles or stress and could talk about their experiences in a thoughtful and articulate way. Twenty-one youth were selected by the staff to participate in the focus groups (11 in one group, Group A, and 10 in the other, Group B). The children's ages ranged from $11-15(M=12.62)$ with one fifth grade student, five $6^{\text {th }}$ grade students, ten $7^{\text {th }}$ grade students, and five $8^{\text {th }}$ grade students. Seven boys and fourteen girls participated in the groups, with 8 girls and 3 boys in group A and 6 girls and 4 boys in group B.

\section{Procedure}

Four 90-minute sessions were held during the after school program at each school. The first session focused on exposure to violence the children experienced, as well as coping strategies utilized. Specific questions asked of the students included: What do you worry about? How do you cope with what you are worried about? The remaining sessions included a brief summary of each curriculum with questions on the usefulness of the materials to be included, the nature of activities (didactic or experiential), whether they had engaged in similar activities in school or through after school activities, church groups, or community organizations, the age appropriateness of the materials, and their interest or excitement level in the curricula. At times, activities identified by the researchers were briefly implemented so that students could provide more detailed comments on them. For example, the facilitators explained an ABC model of conflict resolution and the participants in Group A asked if they could try it. Icebreaker activities were described to both sets of focus groups, and participants asked to be able to complete them.

The sessions were conducted by the African-American female faculty and one or two graduate students from the research team who had been trained in both CST and the CEC curricula. All sessions were audiotaped. Several of the graduate students who had previously administered the CST and CEC for other projects assisted in leading the focus groups. Students who led the sessions processed the focus groups and received feedback. No written information from the curricula review was collected from participants. Griffin and Miller (2007) recommend using incentives in working with groups who may not participate in research as they often feel that their opinions are not valued or respected. Each student received a $\$ 15$ gift card for each session attended. Results from the focus group were used to revise the curricula for implementation in the second phase of the project.

\section{Youth Experience with Exposure to Violence}

\section{Data Collection, Coding and Analysis}

The process of establishing and conducting the focus groups was filled with challenges from the beginning, including establishing school sites to engage the program, difficulties with research review boards, and finding the best times to meet with participants. The project design and implementation was time intensive and required months for meeting and planning selecting appropriate schools, clearing review boards, and engaging with school officials. We found ourselves meeting and planning with the program staff for months selecting appropriate schools and clearing review boards. Time was also spent in training graduate and undergraduate assistants to conduct the focus groups.

Yet, despite the challenges, we were left inspired by the dedication and concern shown by the youth throughout the project, and learned how critical it is that youth voices be heard. The analysis was performed in two distinct waves. First, questions on violence and stress were coded following the first 
two steps of grounded theory approach (Strauss \& Corbin, 1998; Walter \& Myrick, 2006). While theory building was not the goal of the analysis, we wanted to be able to verify the various effects of violence on participants and to determine if certain presuppositions existed. One of the principal investigators independently coded each statement according to content themes. Responses from participants were examined to find emergent themes and categories. Axial coding was used to determine relationships between categories and subcategories (Walker \& Myrick, 2006).

\section{Gems of Insight from African-American Youth Voices}

The first objective in the project was to determine stressors and the level of violence exposure of participants, so the first focus group session included questions on stress in general and the youth's exposure to violence in particular. The most powerful lesson we learned in this project was the importance of including youth perspectives. The majority of participants across both focus groups were very articulate about their perceptions of violence. Specific questions included 1) What are you worried about?, and 2) How do you cope with the things you worry about?

\section{Reality of Exposure to Violence}

The first questions asked children about their worries, things that would make their day bad. The presence of violence is a daily reality for the participants in the study; it was the dominant issue discussed by the participants (95\% in Group A and $85 \%$ in Group B). When asked what types of stressors, anxiety and fears the participants faced in their daily lives, violence was the first listed in both groups. "I'd rather die than be shot" one participant stated (Group A). Another said, "sometimes I am sad because around my house there is shooting and stuff...I worry about whether people will get shot" (Group B). Many participants expressed the fears they had of community and neighborhood violence; fears of making it safely to and from school; and, dangers from men who congregate in front of neighborhood stores ( $90 \%$ in both groups). They also reported fear of gangs; both of being recruited by gangs and being caught in gang crossfire ( $85 \%$, Group A, $80 \%$ Group B). "If I get shot I want to die, because I don't want to deal with the pain or be paralyzed..." The participants were worried about harm for themselves and family members, some of whom had already lost family to violence ( $95 \%$ in both groups). They also felt that children were at particular risk. "People going around raping little kids" was a response of one participant.

\section{Pervasiveness of Violence}

Another theme was the pervasive and inescapable nature of the violence. Many participants commented that watching the news often exacerbated their fears of danger and violence (70\% Group A, 65\% Group B). "(You) see things on TV and that makes you think of things that happen in the neighborhood" (Group A). Another student asked "Did you hear about on the news how the girl got beaten to death and they put her in an alley?" (Group B)

\section{Violence in Schools}

Students also reported concerns with violence in schools, including bullying within the schools (50\% Group A, 70\% Group B). Other stressors were listed by students, including school performance, teacher expectations, student-teacher interactions, and family dynamics (about $45 \%$ of total responses in both groups). However, even in those discussions, it seemed clear that concerns with violence bled into the concerns that most typical adolescents' experience. One participant stated "In this school, they give all their attention to the bad kids...and the next day we have a test or something...how we going to learn if they give all their attention to the bad people?" Participants were realistic about the fact that their anxiety also made it difficult to concentrate on their school work. Finally, several participants stated their fears of remaining in the neighborhood if they failed school and were not able to go to college or obtain 
employment (45\% Group A). "If I am fighting, if the kids fight in school, they say they are gonna take us to jail...and I don't want to go to jail...want to get a good job".

\section{Discussions with Adults Regarding Violence}

The theme of adult unavailability appeared to leave participants feeling alone with their experiences. Participants reported mixed reactions about talking about their feelings and stressors, and indicated that it was not something they often did. "Can we not talk about death?" (Group A). It was clear from the discussions that for most of the children, the focus groups afforded one of few opportunities to process experiences with violence with an adult. When asked about talking about violence with others as a coping mechanism, most students suggested that there were no adults present in their lives with whom they could process either direct or vicarious experiences of violence ( $90 \%$ Group A, $80 \%$ Group B). One youth stated, "(I) don't feel comfortable talking to nobody, so I talk to myself." Some participants reported that they could not discuss violence with their parents because many parents were stressed or unable to cope with their own experiences. Whether this perception is accurate or not, most youth reported that parents rarely initiated discussions of violence unless they were reporting some type of harm to another family member (75\% Group A, 70\% Group B) .

Most of the participants also reported feeling disengaged from teachers, who many felt were only concerned with surviving the day ( $90 \%$ Group A, $85 \%$ Group B). "They don't care about us", and "they yell and curse us out all the time" were sentiments echoed by many participants in the focus groups. Students also were dissatisfied with the administrators in the school building (about $65 \%$ in both groups). And, while they reported feeling supported by the staff from the after-school program, much of the support they reported receiving focused on academic performance, rather than violence or family stressors. Feeling disenfranchised and silenced by adults in their lives left many of the participants feeling more vulnerable to stressors in their lives. This suggests that the direct negative effects from violence exposure may be exacerbated by the lack of opportunity to process these issues with significant adults in their lives, placing them at greater risk for developing internalizing difficulties and externalizing behaviors. Research suggests that youth who have the opportunity to discuss and process traumatic events, including violence, tend to be less affected, promoting resilience (Reese, Vera, Simon, \& Ikeda, 2000).

\section{Curriculum Revisions}

\section{Data Analysis and Coding}

Focus groups have been used as part of CBPAR to develop and adapt curricula to make them more culturally sensitive (Komro et al., 2004; Parsai, Castro, Marsiglia, Harthun, \& Valdez, 2006). This often includes asking a series of questions, analyzing responses for content, and making appropriate adjustments. While we wanted the participants' voice around violence to be included in curriculum revision, we also desired to gain their direct feedback and reactions to the curriculum to make adjustments. For this phase of analysis, field and process notes were used to analyze the content of the responses to the curricula in order to make revisions. When multiple student researchers attended the focus groups, the faculty member took notes on the process of the discussion, who made the suggestions, and the nature of the suggestion. Each student research facilitator took process notes after each focus group. At the completion of the focus groups, the research team members met to discuss the process notes, review tapes, and to revise the curriculum. The notes were analyzed by looking at commonalities between the faculty and student notes for each component of the curriculum. Decisions on altering the curricula were made if notes indicated that the majority (50\% or more) of focus group participants were in agreement with changes, or when the facilitators/observers noticed issues with the way participants responded to the curriculum. 


\section{Results}

The students were quite effective in providing useful and constructive feedback on the curricula, and the process itself became an intervention for the participants. Most of the participants felt honored at being selected to represent youth of their age and to have the responsibility to critique a curriculum that could help other youth. They seemed to take the task of providing feedback seriously and gave very specific recommendations to enhance the curriculum. Of course, participants made suggestions that would typically be expected from pre-adolescents: they wanted to be able to complete all activities during the program and did not want to have homework; they would be interested in guest speakers, but only if they were interesting and not boring; and they would like to expand the discussion of Civil Rights leaders beyond Martin Luther King, Jr. They also wanted to have more activities, including role-plays, skits, and games and competitions and fewer lectures.

\section{Revisions to Coping Skills Training (CST)}

The participants had very specific recommendations for the CST curriculum. The focus group session included an overview of the curriculum and at times demonstrations of particular exercises and activities. Students provided the most feedback on relaxation exercises. We were able to engage the participants in deep breathing and relaxation exercises, along with guided imagery exercises. Surprisingly, many of the participants (about $70 \%$ in Group B) felt that these exercises would be ineffective in reducing the stress from violence, especially grief-related stress, as they often felt overwhelmed or flooded by emotions when thinking of violence. For example, one participant stated, "Breathing exercises don't help everyone." Many participants, in fact, reported engaging in distracting activities as a coping mechanism, such as listening to loud music to drown out gunfire, dancing, rapping, or watching television (85\% Group A, 90\% Group B). The participants thought that being still to engage in deep breathing would create more anxiety. If relaxation exercises were to be included in the curriculum, it would require continuous practice. This supports what we found with the teens with asthma who did not find the relaxation breathing exercises to be helpful but more anxiety-producing (Velsor-Friedrich, Pigott, \& Srof, 2005).

Students were very receptive to problem-solving strategies. We had not intended to practice the restructuring techniques with students, but most in both groups were immediately able to apply current situations in their lives to the materials. The participants discussed stress from test-taking and using strategies to reduce anxiety over performance. Students unanimously believed that this aspect was very applicable to stress reduction around violence issues and concerns.

\section{Revisions to Civic Engagement Curriculum (CEC)}

The participants also provided detailed feedback on the CEC. Again, the CEC was designed to improve the capacity of youth to take better control of themselves through understanding and action, to develop leadership skills and bring about positive change in their communities. The curriculum begins with warm up activities, defining community, and understanding civic action. One unanticipated aspect of the focus group was the need to define civic engagement to participants; this became an important piece of curriculum revision. Participants were very excited about engaging with school administrators, and civic and community leaders to create systemic changes within the schools and communities (85\% in Group A, $90 \%$ Group B). Participants were mixed about studying important African-American leaders; some felt that they had learned enough about Martin Luther King, Jr. (about 50\% of Group A and $60 \%$ in Group B), for example, while others seemed excited about learning about ways he promoted social justice. Students listed President Obama, Rosa Parks, Nelson Mandela, Malcolm X, Sojourner Truth, and Fannie Lou Hammer as alternative figures of interest. Role-playing famous characters, performing historical scenes (drama), and trivia games about African-American history were recommended by the youth ( $70 \%$ in both groups). Students were very interested in learning more about their community, and suggested a scavenger hunt for community resources and offices of local government officials. 


\section{Table 1}

\section{Overview of Curricula}

\begin{tabular}{|c|c|}
\hline Coping Skills Training & Civic Engagement Curriculum \\
\hline $\begin{array}{l}\text { Problem Solving- } \\
\text { Identify stressor in one's life } \\
\text { Describe steps of a problem solving method } \\
\text { Role-play a scenario using the problem solving skills }\end{array}$ & $\begin{array}{l}\text { Civic Engagement introduction- } \\
\text { What is community? } \\
\text { Overview of violence } \\
\text { Create community within group }\end{array}$ \\
\hline $\begin{array}{l}\text { Communication \& Social Skills- } \\
\text { Importance of communicating clearly, effectively, and } \\
\text { respectfully with others } \\
\text { Review aspects of communication } \\
\text { Types of communication styles } \\
\text { The use of I-messages } \\
\text { Role-play a scenario using new communication skills }\end{array}$ & $\begin{array}{l}\text { Getting informed- } \\
\text { History of issues } \\
\text { Solutions from other cities, countries } \\
\text { Description of current problem- Who is involved; } \\
\text { financial aspects, cost to society } \\
\text { Legal aspects } \\
\text { Review and critique of current }\end{array}$ \\
\hline $\begin{array}{l}\text { Managing Stress- } \\
\text { Define stress and identify stressors in students' lives } \\
\text { Describe some physical manifestations of stress. } \\
\text { Identify the roles that each student has } \\
\text { Discuss how to try and achieve balance within multiple } \\
\text { roles } \\
\text { Describe methods for reducing stress } \\
\text { Role-play a scenario using new managing stress skills }\end{array}$ & $\begin{array}{l}\text { Getting engaged- } \\
\text { Development of community project } \\
\text { Interview local officials }\end{array}$ \\
\hline $\begin{array}{l}\text { Conflict Resolution- } \\
\text { Define the term conflict } \\
\text { Discuss the goal of conflict resolution: win-win } \\
\text { Types of conflict styles } \\
\text { Role-play a scenario using new conflict resolution skills }\end{array}$ & \\
\hline $\begin{array}{l}\text { Behavior Modification/Cognitive Restructuring- } \\
\text { Describe ways to assess and evaluate one's behavior; } \\
\text { set goals; arrange environment to encourage goal } \\
\text { attainment; reward self when goals are achieved } \\
\text { Use problem solving skills to help change behaviors } \\
\text { and achieve goals } \\
\text { Discuss the use of "self-talk" to help change behaviors } \\
\text { Role-play a scenario using new behavior modification } \\
\text { skills }\end{array}$ & \\
\hline
\end{tabular}




\section{Implications and Limitations of this Work}

\section{Importance of Systemic Interventions}

The process of conducting, and the responses generated from, the focus groups reinforced the importance of implementing system-wide interventions to address community violence (Vera, 2007). As with any CBPAR, it was critical that the key stakeholders were contacted prior to beginning the research to provide support of the program, and more importantly to be able to connect with the research participants. Investigators must have knowledge of the community to both establish positive working relationships with members of the community and develop and implement programs that are valued by the community in order to engage in culturally relevant research (Griffin \& Miller, 2007; Reese \& Vera, 2007).

Although the revised curricula may have a positive influence on individuals' ability to cope, an ecosystemic approach to reducing violence is also necessary. The participants in the focus groups were eager to learn about how to create and strengthen communities within the school and their neighborhoods. Participants were very interested in defining and discussing what comprises a community. They wanted to develop strategies to discover more about community leaders and resources. We led a discussion on classroom safety, and participants initially thought we were discussing behaviors to promote safety in school (i.e., "not running with scissors"). When we discussed considering the classroom as a community with a set of rules to promote safety and reduce negative behaviors such as bullying, the participants were very responsive. They reported being very interested in discussing how to make their schools/classrooms safe and respectful communities. Given our lack of access to school personnel, our approach to the CBPAR was limited to the youth's perspective.

One area that was not adequately addressed by us in the focus groups was the role of parents in either protecting participants from exposure to violence or the effects of violence exposure. We did not ask a specific question about parents or adults, but participants in each group spontaneously included the role of families and teachers in their responses on coping. Families can also serve as a protective factor through decreasing the probability that a youth is exposed to risk factors for violence and by limiting the consequences of such exposure to risk factors when they occur (Hammack, et al, 2004; Reese, et al., 2000). Participants indicated that they did not discuss issues of violence frequently, but were open to components of the curricula that fostered social support systems, including parents and other family members.

Finally, the participants addressed their realistic fears and concerns around violence and safety. They reported that they would benefit from concrete solutions on how to stay away from violence. Walking to and from school, going to neighborhood stores, and being outside after dark often placed them at great risk for receiving or witnessing violence. Escort services to school only provided one outlet of safety for students. Participants also indicated concerns with police and their involvement with violence. Most did not feel protected by police because police were unresponsive or slow to respond. For example, one student noted that the police "do nothing about people going around killing people." Students also felt that they were at risk to become victimized by police through acts of oppression or racism or by being assumed to be gang members.

\section{Conclusion and Future Directions}

We have an obligation to promote social justice for disenfranchised groups, especially children and youth. The lessons learned from this first phase of the project are connected to concepts of social justice. The first lesson was the importance of giving voice to youths' experience that led to critical dialogue and evaluation of their experiences. One method of keeping people disenfranchised is to prevent them the 
opportunity to speak or present their issues. The focus group experience seemed to give participants a new vocabulary and way of discussing issues. The students were able to use the materials and activities to begin to figure out how to improve their school and neighborhood communities. The other component of providing "voice" to participants is that they were able to provide suggestions to ensure that the curricula were culturally relevant. Individuals interested in promoting social justice and safe communities for youth need to include youth voice in the development of interventions.

The second major lesson was the importance of a systemic approach to working to reduce the negative effects of violence on African-American youth. Speight and Vera (2004) state that the primary purpose of social advocacy is the attainment of justice for exploited, dominated, and marginalized people and communities; approaches that include multiple levels of the ecosystem will prove most beneficial to atrisk groups. Participants in the focus groups commented on the lack of social support they felt from multiple sources as they sought to cope with exposure to violence. Efforts to both reduce violence and the effects of exposure to violence need to include individuals, families, school systems, communities, and public policy and legislation. Synchronized interventions for youth, parents, and teachers seem to be critical for helping to reduce violence and to help youth to foster resilience. Advocacy and outreach also are needed to address sociopolitical and economic causes of violence. Critical components of social justice advocacy include working in communities, schools, and religious institutions, increasing mental health services and access to services, and creating systemic interventions to inform public policy.

A social justice perspective emphasizes societal concerns, including issues of equity, self-determination, interdependence, and social responsibility (Vera \& Speight, 2003). We hope through the revised curricula and programs to truly promote social justice in the area of violence prevention through promoting selfdetermination and civic engagement. We recognize it is but one step in the approach to empower youth. Issues of equity and social responsibility need to be addressed. Our next steps include evaluating the revised curricula for effectiveness. We are also planning strategies to include parents, teachers and school administrators, and community leaders as guided by our youth participants. We will promote advocacy for youth who often remain voiceless by empowering them to develop self-determination and coping skills to create safer communities. It is our hope that other researchers and service providers can take the lessons learned from this project to continue to help communities from the inside.

Contact information:

Anita Thomas

School of Education, 820 N. Michigan Avenue, Chicago, IL, 60611

athoma9@luc.edu

(312) 915-7403 


\section{References}

Aisenberg, E., \& Herrenkohl, T. (2008). Community violence in context: Risk and resilience in children and families. Journal of Interpersonal Violence, 23(3), 296-315. doi:10.1177/0886260507312287

Ambrosino, J. M., Fennie, K. P., Whittemore, R., Jaser, S. S., \& Grey, M. (2008). Short-term effects of coping skills training in school age children with type 1 diabetes. Pediatric Diabetes, $9(3$ Pt 2), 74-82.

Berton, M. W., \& Stabb, S. D. (1996). Exposure to violence and post-traumatic stress disorder in urban adolescents. Adolescence, 31, 489-496.

Boyce, C., Robinson, W., \& Richards, M. H. (2011). Burgeoning directions for the prevention of youth violence. Journal of Prevention \& Intervention In The Community, 39, 93-97. doi:10.1080/10852352.2011.556554

Bryant, T. (2000, October). Together by choice: Black girls creating opportunities to empower themselves through participatory action research. Dissertation Abstracts International Section A, 61.

Caldwell, C., Rafferty, J., Reischl, T., Loney, E., \& Brooks, C. (2010). Enhancing parenting skills among nonresident African American fathers as a strategy for preventing youth risky behaviors. American Journal of Community Psychology, 45(1/2), 17-35. doi: 10.1007/s10464-009-9290-4

Ceballo, R., Dahl, T.A., Aretakis, M.T., \& Ramirez, C. (2001). Inner-city children's exposure to community violence: How much do parents know? Journal of Marriage and Family, 63, 927-940.

Center for Disease Control and Prevention, National Center for Injury Prevention and Control. Web-based Injury Statistics Query and Reporting System (WISQARS) [online]. (2010). Retrieved from www.cdc.gov/injury/wisqars/index.html

Centers for Disease Control and Prevention (2009). Youth risk behavioral surveillance-United States, 2009. MMWR 2010; 59 (No. SS-5).

Cooley-Quille, M., Boyd, R., Frantz, E., \& Walsh, J. (2001). Emotional and behavioral impact of exposure to community violence in inner-city adolescents. Journal of Clinical Child Psychology, 30, 199206. doi: $10.1207 / S 15374424 J C C P 3002 \_7$

Costa, J., Herbert, C., \& Macaulay, A. C. (2004). Participatory research in primary care. Journal of Interprofessional Care, 18, 451-453. doi: 10.1080/13561820400010588

Edlynn, E., Gaylord-Harden, N., Miller, S., \& Richards, M. (2008). African American inner-city youth exposed to violence: Coping as a moderator for anxiety. Journal of Orthopsychiatry, 78, 249-258. doi: $10.1037 / \mathrm{a} 0013948$

Eno, J., \& Shaker, R. (2008). Mapping connections project. Retrieved from: http://mappingconnections.com/projects.php

Fitzpatrick, K. M., \& Boldizar, J. P. (1993). The prevalence and consequences of exposure to violence among African American youth. Journal of the American Academy of Child and Adolescent Psychiatry, 32, 424-430. doi: 10.1097/00004583-199303000-00026

Forman, S. G. (1993). Coping skills for children and adolescents. San Francisco, CA: Jossey-Bass. 
Fowler, P. J., Tompsett, C. J., Braciszewski, J. M., Jacques-Tiura, A. J., \& Baltes, B. B. (2009). Community violence: A meta-analysis on the effect of exposure and mental health outcomes of children and adolescents. Development and Psychopathology, 21, 227-259. doi: 10.1017/S0954579409000145

Garbarino, J., Hammond, R., Mercy, J., \& Yung, B. R. (2004). Community violence and children: Preventing exposure and reducing harm. In K. I. Maton, C. J. Schellenbach, B.J. Leadbeater, \& A. L. Solarz (Eds.), Investing in children, youth, families, and communities (pp. 13-30). Washington, DC: American Psychological Association.

Glodich, A. (1998). Traumatic exposure to violence: A comprehensive review of the child and adolescent literature. Smith College Studies in Social Work, 68, 321-345. doi:10.1080/00377319809517534

Gorman-Smith, D., \& Tolan, P. (1998). The role of exposure to community violence and developmental problems among inner-city youth. Development and Psychopathology, 10, 101-116. doi:10.1017/S0954579498001539

Grey, M., Boland, E., Davidson, M., Li, J., \& Tamborlane, W. (2000). Coping skills training for youth with diabetes mellitus has long-lasting effects on metabolic control and quality of life. The Journal of Pediatrics, 137, 107-113.

Grey, M., Boland, E., Davidson, M., Yu, C., \& Tamborlane, W. (1999). Coping skills training for youths with diabetes on intensive therapy. Applied Nursing Research, 12, 3-12.

Griffin, J. P., Jr., \& Miller, E. (2007). Community-based programs prevention: Scientific and practical considerations for a research practitioner's perspective on culturally relevant research. The Counseling Psychologist, 35, 850-859. doi:10.1177/0011000007307999

Hammack, P. L., Richards, M. H., Luo, Z., Edlynn, E. S., \& Roy, K. (2004). Social support factors as moderators of community violence exposure among inner-city African American young adolescents. Journal of Clinical Child and Adolescent Psychology, 33(3), 450-462. doi:10.1207/s15374424jccp3303_3

Hammond, W. R., \& Arias, I. (2011). Broadening the approach to youth violence prevention through public health. Journal of Prevention and Intervention in the Community, 39, 167-175. doi: 10.1080/10852352.2011.556574

Johnson, R. L. (2006). The National Institutes of Health (NIH) State-of-the-Science conference statement on preventing violence and related health-risking social behaviors in adolescents - A commentary. Journal of Abnormal and Child Psychology, 34, 471-474.

Klaus, P., \& Rennison, C. M. (2002). Age patterns in violent victimization, 1976-2002 (NCJ 190104). Washington, DC: U.S. Department of Justice, Office of Justice Programs, Bureau of Justice Statistics.

Komro, K.A., Perry, C.L., Veblen-Mortensen, S., Borsma, L.M., Dudovitz, B.S., Williams, C.L., Jones-Webb, R., \& Toomey, T.L. (2004). Brief report: The adaptation of Project Northland for urban youth. Journal of Pediatric Psychology, 29(6), 457-466. doi: 10.1093/jpepsy/jsh049

Larson, R. W. (2000). Toward a psychology of positive youth development. American Psychologist, 55, 170-183. 
Marcus, M., Walker, T., Swint, J., Smith, B., Brown, C., Busen, N., et al. (2004). Community- based participatory research to prevent substance abuse and HIV/AIDS in African-American adolescents. Journal of Interprofessional Care, 18, 347-359.

Mazza, J. J., \& Reynolds, W. M. (1999). Exposure to violence in young inner-city adolescents: Relationships with suicidal ideation, depression, and PTSD symptomatology. Journal of Abnormal Child Psychology, 27, 203-213.

The National Center for Children Exposed to Violence. Community violence. Retrieved from http://www.nccev.org/violence/community.html

Overstreet, S., \& Braun, S. (2000). Exposure to community violence and post traumatic stress symptoms: Mediating factors. American Journal of Orthopsychiatry, 70, 263-271.

Ozer, E. J., Cantor, J. P., Cruz, G. W., Fox, B., Hubbard, E., \& Moret, L. (2008). The diffusion of youth-led participatory research in urban schools: The role of the prevention support system in implementation and sustainability. American Journal of Community Psychology, 41, 278-289. doi: $10.1007 /$ s10464-008-9173-0

Parham, T. A., \& McDavis, R. J. (1987). Black men, an endangered species: Who's really pulling the trigger? Journal of Counseling and Development, 66, 24-27.

Parsai, M.B. Castro, F.G., Marsiglia, F.F., Harthun, M.L., \& Valdez, H. (2011). Using community based participatory research to create a culturally grounded intervention for parents and youth to prevent risky behaviors. Prevention Science, 12(1), 34-47.

Reese, L. E., \& Vera, E. M. (2007). Culturally relevant prevention: The scientific and practical considerations of community-based programs. The Counseling Psychologist, 35, 763-778. doi: $10.1177 / 0011000007304588$

Reese, R. E., \& Vera, E. M., Simon, T. R., \& Ikeda, R. M. (2000). The role of families and care givers as risk and protective factors in preventing youth violence. Clinical Child and Family Psychology Review, 3, 61-77. doi: 10.1023/A:1009519503260

Richards, M. H., Cornelli, R., Celio, C. I., Choi, I., Grant, J., \& Segal, C. (Revise and resubmit). Servicelearning in early adolescence: Results of a school-based curriculum. Journal of Experiential Learning.

Sampson, R. J., Raudenbush, S. W., \& Earls, F. (1997). Neighborhoods and violent crime: A multilevel study of collective efficacy. Science, 270, 918-924.

Sanderson, R. C., \& Richards, M. H. (2010). The after-school needs and resources of a Chicago community: Surveying youth and parents for community change. American Journal of Community Psychology, 45, 430-440. doi: 10.1007/s10464-010-9309-x

Schwab-Stone, M. E., Ayers, T. S., Kasprow, W., Voyce, C., Barone, C., Shriver, T., et al. (1995). No safe haven: A study violence exposure in an urban community. American Academy of Child and Adolescent Psychiatry, 34, 1343-1352. doi: 10.1097/00004583-199510000-00020

Schwartz, D., \& Gorman, A. H. (2003). Community violence exposure and children's academic functioning. Journal of Educational Psychology, 95, 163-173. doi: 10.1037/0022-0663.95.1.163 
The Search Institute. (2006). Forty developmental assets for adolescents. Retrieved from http://www.search-institute.org/content/40-developmental-assets-adolescents-ages-12-18

Speight, S. L., \& Vera, E. M. (2004). A social justice agenda: Ready, or not? The Counseling Psychologist, 32, 109-118. doi: 10.1177/0011000003260005

Stein, B. D., Jaycox, L. H., Kataoka, S., Rhodes, H. J., \& Vestal, K. D. (2003). Prevalence of child and adolescent exposure to violence. Clinical Child and Family Psychology Review, 6, 247-263.

Strauss, A., \& Corbin , J. M. (1998). Basics of qualitative research: Techniques and procedures for developing grounded theory ( $2^{\text {nd }}$ ed.). Thousand Oaks, CA: Sage.

Sweeney, C., Goldner, J., \& Richards, M. (in press, 2011). Daily emotional experience and exposure to violence. Journal of prevention and Intervention in the Community (Special Issue: Innovative Community-based Approaches to Violence Prevention for Urban Youth).

Trickett, P., Duran, L., \& Horn, L. (2003). Community violence as it affects child development: Issues of definition. Clinical Child and Family Psychological Review, 6(4), 223-236. doi: 10.1023/B:CCFP.0000006290.91429.75

Tuma, F., Loeber, R. I., \& Lochman, J. (2006). Introduction to special section on the National Institute of Health State of the Science Report on Violence Prevention. Journal of Abnormal Child Psychology, 34, 451-456. doi: 10.1007/s10802-006-9039-6

Velsor-Friedrich, B., Pigott, T., \& Srof, B. (2005). A practitioner-based asthma intervention program with African-American inner city school children. Journal of Pediatric Health Care, 19, 163-172. doi:10.1016/j.pedhc.2004.12.002

Vera, E. M. (2007). Culture, prevention, and the politics of disparities. The Counseling Psychologist, 35, 860-867. doi: $10.1177 / 0011000007306532$

Walker, D., \& Myrick, F. (2006). Grounded theory: and exploration of process and procedure. Qualitative Health Research, 16, 547-559. doi: 10.1177/1049732305285972

Weist, M. D., Acosta, O. M., \& Youngstrom, E. A. (2001). Predictors of violence exposure among innercity youth. Journal of Clinical Child Psychology, 30, 187-198. Doi: 10.1207/S15374424JCCP3002_6 